\title{
A DIGNIDADE DA PESSOA HUMANA COMO LIMITAÇÃO AO DISCURSO DO ÓDIO: um caminho da fraternidade
}

\author{
Ana Patricia Vieira Chaves Melo* \\ Bricio Luis da Anunciação Melo*
}

RESUMO: No âmbito de um ordenamento jurídico constitucionalizado, em um Estado Democrático de Direito, as expressões de discurso do ódio não devem ser toleradas. Tais manifestações de intolerância privam seus destinatários, geralmente membros de uma minoria, de direitos constitucionais e dos espaço públicos democráticos, de modo que a liberdade de expressão deve sofrer restrições a fim de garantir mais do que tolerância - a fraternidade, concebida como princípio jurídico e fruto do pleno desenvolvimento da dignidade da pessoa humana. Utiliza-se o método hipotético dedutivo, com lastro em pesquisa bibliográfica, nas normas constitucionais e tratados internacionais.

Palavras-chave: Discurso do ódio. Intolerância. Liberdade de expressão. Dignidade da pessoa humana. Fraternidade.

\section{THE DIGNITY OF THE HUMAN PERSON AS A LIMITATION TO THE HATE: a path of the fraternity}

\begin{abstract}
In the context of a constitutional legal order, in a democratic state of law.the expression of hate speech should not be tolerated. These manifestations of intolerance deprive its victims, usually members of a minority, of constitutional rights and of democratic public spaces, so that freedom of expression must be restricted in order to guarantee more than tolerance - fraternity, conceived as a legal principle and fruit of the full development of the dignity of the human person.The hypothetical deductive method is used, with ballast in bibliographical research, constitutional rules and international treaties.
\end{abstract}

Keywords: Hate speech. Intolerance. Freedom of expression. Dignity of the human person. Fraternity.

\footnotetext{
* Mestranda em Constitucionalização do Direito pela Universidade Federal de Sergipe. Especialista em Direito tributário Pela Universidade do Sul da Santa Catarina. Promotora de Justiça.

* Mestrando em Constitucionalização do Direito pela Universidade Federal de Sergipe. Especialista em Direito tributário Pela Universidade do Sul da Santa Catarina. Professor Convidado da Pós Graduação em Direito da Estágio/SE.
} 
1 Introdução

O direito fundamental à liberdade de expressão assumiu papel central no conceito de Democracia ocidental e alcançou relevância no plano dos tratados internacionais. Sob a égide da Constituição Federal de 1988, promoveu-se uma constitucionalização dos direitos, irradiando os efeitos das normas constitucionais aos outros ramos do ordenamento jurídico, e salvaguardou-se a liberdade de expressãono artigo $5^{\circ}, \mathrm{IV}^{1}$, sob o manto da liberdade da manifestação de pensamento, com a característica de cláusula geral.

Ademais, foram previstos, em dispositivos específicos, a liberdade de expressão religiosa, a liberdade de ensino e pesquisa, a livre expressão da atividade intelectual, artística e de comunicação, a liberdade de comunicação e informação, entre outras. Garantiramse também mecanismos de efetividade à liberdade de expressão, tais como a proibição da censura e do anonimato, indenização por dano moral e material em caso de violação e o direito de reposta.

Ocorre que, sob o manto de realização dos objetivos fundamentais da liberdade de expressão - busca da verdade, garantia da democracia, autonomia e auto-realização individual (SARMENTO, 2006, p. 94), podem proteger-se manifestações de intolerância ${ }^{2}$ e discriminação em virtude de raça, cor, etnicidade, identidade cultural, nacionalidade, sexo, orientação sexual, religião, origem social, condição de migrante, refugiado, repatriado, apátrida, deficiência, dentre outros fatores, violando os princípios jurídicos da dignidade da pessoa humana e da fraternidade previstos no ordenamento jurídicos brasileiro.

Destarte, analisar-se-á, em um primeiro momento, o conceito e características discurso do ódio, com base em instrumentos internacionais - em especial a Convenção Interamericana contra Todas Formas de Discriminação e Intolerância - e na doutrina brasileira e comparada. A partir desse suporte teórico, verificar-se-á se tal discurso merece proteção à luz da Constituição pátria, considerandoos princípios da dignidade da pessoa humana e da

\footnotetext{
1“Art. 5, IV - é livre a manifestação do pensamento, sendo vedado o anonimato; [...]” (BRASIL, 1988).

${ }^{2}$ Adotado o conceito de intolerância do artigo 1, da Convenção Interamericana contra o Racismo, a

Discriminação Racial e Formas Correlatas de Intolerância: “6. Intolerância é um ato ou conjunto de atos ou manifestações que denotam desrespeito, rejeição ou desprezo à dignidade, características, convicções ou opiniões de pessoas por serem diferentes ou contrárias. Pode manifestar-se como a marginalização e a exclusão de grupos em condições de vulnerabilidade da participação em qualquer esfera da vida pública ou privada ou como violência contra esses grupos.” (OEA, 2013).
} 
fraternidade nela plasmados, e dos instrumentos internacionais de direitos humanos. Nesse sentir, estabelecer-se-ão, no contexto do discurso do ódio, os limites do direito fundamental à liberdade de expressão ante o princípio da dignidade da pessoa humana, em um contexto de Estado Democrático de Direito e de sociedade fraternal.

Por fim, será analisado se é possível garantir, à luz do princípio da fraternidade, o discurso dos intolerantes em prol da democracia, sem privar os seus destinatários, geralmente membros de uma minoria, de seus direitos constitucionais, em especial a dignidade da pessoa humana.

Para tanto, utilizar-se-á o método hipotético dedutivo, com lastro em pesquisa bibliográfica, na doutrina nacional e comparada, a respeito do discurso do ódio e os limites da liberdade de expressão, ante os princípios jurídicos da dignidade da pessoa humana e da fraternidade, na seara constitucionalista e filosófica, centralizada na temática dos direitos fundamentais, bem como nas normas constitucionais e tratados internacionais.

\section{0 discurso do ódio no contexto internacional e brasileiro}

Em uma sociedade regida pelo pluralismo de ideias, surge, em múltiplas versões, o discurso do ódio, entendido como a manifestação de ideias intolerantes, preconceituosas e discriminatórias contra indivíduos ou grupos vulneráveis, com o escopo de ofender-lhes a dignidade e incitar o ódio.

A temática do discurso do ódio ganha especial relevância no contexto mundial atual. Na Europa, enfrenta-se a crise dos refugiados sírios, cujo acolhimento tem sido negado sistematicamente por alguns países europeus ou tem seus acampamentos desmantelados em outros (CAÑAS, 2016). Ademais, multiplicam-se as deportações de refugiados diante da mudança na política migratória adotada pela União Europeia (SAHUQUILLO, 2016).

Some-se a isso protestos de pais locais na Grécia contra a escolarização de crianças refugiadas, a provocar rejeição social. Neste último caso, crianças refugiadas estudam em um horário distinto, sem nem mesmo se encontrar com seus supostos colegas de classe, e as garantias das autoridades de que estão vacinados não tranquilizaram os pais. Há, ainda, casos extremos como o ocorrido na ilha de Quios, onde os pais convocaram um referendo sobre o assunto, ou no povoado de Volvi, perto de Salonica - onde, em meio a protestos nacionalistas, 
os moradores fecharam com cadeados as portas da escola e deixaram seus filhos em casa para evitar que se misturassem com os refugiados (SÁNCHEZ-VALLEJO, 2016).

Ainda no contexto europeu, operou-se o recente atentado terrorista que atingiu o jornal satírico francês Charlie Hebdo ${ }^{3}$ em 7 de janeiro de 2015, em Paris. Ao retratar charges do profeta Maomé, foi recebida como um insulto aos mulçumanos e incitação ao preconceito contra os árabes, por caracterizá-los como terroristas, desencadeando esta suposta forma de protesto contra a edição Charia Hebdo, de modo a trazer à lume a importânciade se estabelecerem os limites da liberdade de expressão em face do discurso do ódio. Atualmente, os efeitos deste nefasto acontecimento na França podem ser observados em um aumento da intolerância religiosa, na ampliação das desconfianças em relação à comunidade islâmica e no fortalecimento da extrema direita.

Nos Estados Unidos, a campanha do republicano Donald Trump foi fortemente marcada por discursos xenófobos e racistas, de intolerância contra judeus, mulçumanos e imigrantes, perpassando a promessa de construção de um muro na fronteira do México com os Estados Unidos com o objetivo de conter a imigração ilegal. Após sua vitória, recrudescem entre a população, em especial nas escolas e universidades, o discurso e as práticas de intolerância.Na Califórnia, nos dias que antecederam a eleição presidencial dos Estados Unidos da América, escreveu-se com spray na parede de uma escola com estudantes predominantemente latinos as mensagens: “construam o muro mais alto” (BORGES, 2016).

No cenário nacional, é corrente a circulação nas redes sociais de mensagens de ódio espalhadas contra nordestinos, como o que se verificou contra o juiz sergipano após decisão judicial de bloqueio do whatsapp (SANTANA, 2016), bem como contra miss brasileira 2017 recém-eleita em virtude de sua origem nordestina (MAIA, 2017).

Nesse diapasão, o fenômeno do discurso de ódio deve ser compreendido a partir de dois elementos básicos: discriminação e externalidade, como uma manifestação segregacionista, lastreada na dicotomia superior (emissor) e inferior (atingido), cujo conhecimento seja compartilhado com terceiros (SILVA et al., 2011, p. 445-467). A Convenção Interamericana contra Todas Formas de Discriminação e Intolerância estabelece, em seu artigo $4^{\text {o }}$, parâmetros para a compreensão do conceito de discurso do ódio. Confira-se:

\footnotetext{
${ }^{3}$ Charlie Hebdo é um jornal semanal satírico francês.
} 
Os Estados comprometem-se a prevenir, eliminar, proibir e punir, de acordo com suas normas constitucionais e com as disposições desta Convenção, todos os atos e manifestações de discriminação e intolerância, inclusive: I. apoio público ou privado a atividades discriminatórias ou que promovam a intolerância, incluindo seu financiamento; II. publicação, circulação ou difusão, por qualquer forma e/ou meio de comunicação, inclusive a internet, de qualquer material que: a) defenda, promova ou incite o ódio, a discriminação e a intolerância; e b) tolere, justifique ou defenda atos que constituam ou tenham constituído genocídio ou crimes contra a humanidade, conforme definidos pelo Direito Internacional, ou promova ou incite a prática desses atos; III. violência motivada por qualquer um dos critérios estabelecidos no artigo 1.1; [...] (OEA, 2013).

Destarte, não é qualquer ofensa a um grupo que enseja a sua caracterização, pelo que "deve ser mais que uma manifestação de antipatia, deve indicar a hostilidade contra determinado grupo” (DIAZ, 2011, apud SCHÄFER, 2015, p. 144).Daniel Sarmento (2006, p. 54-55) define o fenômeno como "manifestações de ódio, desprezo ou intolerância contra determinados grupos, motivada por preconceitos ligados à etnia, religião, gênero, deficiência física ou mental ou orientação sexual, dentre outros fatores [...]”.

Nesse ínterim, questiona-se qual o âmbito de proteção e quais os limites do direito fundamental à liberdade de expressão e até que ponto pode-se restringi-lo a fim de resguardar a dignidade humana ou mesmo garantir o discurso dos intolerantes em prol da democracia. Mutatis mutandis, a expressão de discursos do ódio deve ser tolerada em um Estado Democrático de Direitoem prol da democracia, ou é apta a causar danos sérios aos seus destinatários, geralmente membros de uma minoria, privando-os de sua dignidade humana, de modo que deve sofrer restrições?

\section{Discurso do ódio na doutrina comparada e jurisprudência nacional}


Na doutrina comparada, o enfrentamento do discurso do ódio apresenta-se sob perspectiva e pressupostos completamente distintos nos Estados Unidos e na Alemanha, para mencionar países onde a doutrina comparada desenvolveu-se de forma profícua, haja vista a realidade histórica e casos emblemáticos destes países. Em uma abordagem de julgados relevantes para o tema nos Estados Unidos, Daniel Sarmento (2006, p. 63) assevera que, no modelo norte-americano, pautado em uma concepção formal e instrumental de liberdade, o direito à liberdade de expressão deve também proteger a difusão de ideias desprezadas pela maioria, como o racismo. Assim, as limitações à liberdade de expressão cingem-se aos casos de incitação à prática de atos violentos ou ao uso de fightingwords ${ }^{4}$, desde que o discurso represente um perigo claro e iminente (clearand presente danger) de uma ação concreta que venha violar um direito fundamental. Para os demais casos, o remédio contra más ideias deve ser mais discussão e não a censura. Destarte, atribui-se uma posição preferencial à liberdade de expressão na arquitetura dos direitos fundamentais, ignorando-se "a força silenciadora que o discurso opressivo dos intolerantes pode provocar sobre seus alvos” (SARMENTO, 2006, p. 70). Com efeito, a liberdade de expressão assume, no contexto estadunidense, uma posição preferencial - preferred position -em relação aos direitos fundamentais individualmente considerados (BARROSO, 2004, p. 20).

Desde o julgamento do caso Brandemburg vs. Ohio (U.S. SUPREME COURT, 1969), a Suprema Corte norte-americana considerou acobertados pela liberdade de expressão discursos de ódio e racistas de um líder da KuKluxKlan contra negros e judeus, em rede de televisão. No precedente, declarou inconstitucional lei do Estado de Ohio, por considerar que ela punia a defesa de uma ideia. De acordo com esse entendimento, ideias racistas podem ser livremente defendidas, caso não sejam direcionadas e adequadas à prática de atos violentos.

Por outro lado, na tradição doutrinária e jurisprudencial alemã, diversamente do modelo americano, adota-se, desde o paradigmático caso Lüth, a doutrina da eficácia horizontal nas relações entre particulares, ainda que tal eficácia seja indireta, segundo

\footnotetext{
4 "As "palavras de luta" são entendidas, portanto, como uma categoria estreitamente definida de expressões que, na qualidade de mero insulto, podem causar uma briga por constituírem nada mais do que um chamado à violência física. Para se encaixar nessa definição, contudo, uma expressão deve ter baixíssimo apelo deliberativo, por assim dizer, i.e., não pode ter chance de ser entendida como um convite à troca de ideias.” (SILVA, 2015, p. 42). A doutrina da fightingwordsfoi elaborada pela Suprema Corte americana no caso Chaplinsky vs. New Hampsphire(U.S. SUPREME COURT, 1942) e relativizada no precedente R.A.V. vs. City of St. Paul (U.S. SUPREME COURT, 1992), em favor da proteção às manifestações de racismo.
} 
entendimento majoritário (SILVA, 2014, p. 81). Sob esse pressuposto e, diante das nefastas consequências do nacional-socialismo, o direito alemão prevê a criminalização, no plano infraconstitucional, da incitação ao ódio, insulto ou ataque à dignidade humana de partes da população ou de grupos identificados pela nacionalidade, raça, etnia ou religião. Ademais, a dignidade da pessoa humana tem posição central na Lei Fundamental da Alemanha e, não obstante se resguarde a liberdade de expressão, o modelo alemão submete-a a ponderações diante de colisões de direitos, repudiando o discurso do ódio. Winfried Brugger (2007, p. 136) pontua, de forma brilhante, a distinção do tratamento do discurso do ódio nos sistemas norteamericano e alemão: "O sistema jurídico americano proíbe o discurso do ódio o mais tarde possível - apenas quando há perigo iminente de atos ilícitos. A jurisprudência alemã coíbe o discurso do ódio o mais cedo possível”.

No contexto nacional, não se enfrenta a outrora censura à liberdade de imprensa, tal como se deu durante o regime militar, sem menoscabar a existência de outras problemáticas, tais como a monopolização dos meios de comunicação. No entanto, surgem casos difíceis de conflito entre o direito fundamental à liberdade de expressão e outros direitos constitucionais, tais como a igualdade substancial e a dignidade da pessoa humana, delineandose a necessidade de se estabelecerem parâmetros e caminhos para que o legislador e o judiciário possam enfrentar tais questões numa perspectiva humanista.

\section{O humanismo jurídico e a construção histórica do conceito de dignidade da pessoa humana}

O humanismo tem por cerne principal o valor e a dignidade humanos. Segundo Antônio Carlos Wolkmer (2005, p. X), o humanismo envolve uma visão de mundo que, inspirada no valor da natureza humano, é capaz de motivar formas de organização social pautadas na preservação e na promoção da dignidade do homem.

Haja vista o Direito descansar sobre uma concepção de homem e sobre um sistema de valores, pensar o humanismo jurídico implica pensar, compartilhar e resguardar seus direitos fundamentais, como a dignidade humana, justiça, liberdade, direitos humanos, bemcomum, igualdade, fraternidade e segurança individual e social (WOLKMER, 2005, p. XI). Ao 
investigar a influência dos princípios humanistas de juristas e filósofos ao longo da tradição ocidental, Wolkmer conclui que não há um único humanismo, mas uma variedade deles.

Na antiguidade, já se verificavam elementos do humanismo. No pensamento helenístico, Protágoras afirmou ser o “o Homem a medida de todas as coisas”, enaltecendo o ser humano (SARMENTO, 2016, p. 18). Na peça de Sócrates, Antígona, movida pelo amor fraterno, invocou as leis cósmicas para se opor às leis da cidade na defesa de um direito cósmico de ser sepultado com todas tradições fúnebres. Segundo Antônio Carlos Wolkmer (2005, p. 4), essa obra é símbolo de um humanismo de resistência.

Entretanto, falta aos antigos o conceito de pessoa. Desconhece-se a noção de dignidade da pessoa humana, inerente ao homem, restringindo-se a concepção de homem à de cidadão educado para servir à comunidade, titular de direitos fundamentados em uma lei natural cósmica. Mesmo Aristóteles, que desenvolve a justiça como virtude ética, elaborando conceitos referenciais sobre justiça distributiva e compensatória, vincula o princípio da justiça a homens iguais, com capacidade para as práticas cíveis, restrita, pois, a uma minoria aristocrática (WOLKMER, 2005, 1- 13). Cícero ${ }^{5}$, malgrado tenha conferido caráter mais universalista ao humanismo, referindo-se à dignidade como característica de todas as pessoas, coadunava com o sistema escravocrata. Com efeito, no pensamento greco-romano da antiguidade clássica, a escravidão e a completa subordinação da mulher ao homem eram aceitas, porquanto imperava a ideia de desigualdade intrínseca aos seres humanos (SARMENTO, 2016, p. 31).

A origem do humanismo jurídico remonta ao pensamento cristão. Malgrado na tradição greco-romana se reconhecesse a possibilidade de invocar leis cósmicas, transcendentes às leis impostas pela polis, somente o pensamento cristão reconheceu em cada pessoa o valor da vida e a dignidade, abrangendo todo o gênero humano (SAYEG; BALERA, apud MACHADO, 2014, p. 57). Neste contexto, destaca-se o pensamento tomista sobre justiça e bem comum, bem como o seu conceito de superioridade humana fundada no livre arbítrio.

No século XVI, com Pico della Mirandola, pensador renascentista italiano, autor da obra canônica Dignidade do Homem, já se delineia nova compreensão da dignidade humana, antropocêntrica, fundamentada na autonomia individual, concebida como capacidade de realizar escolhas de vida (MACHADO, 2014, p. 160).

No período moderno, sob o influxo do Iluminismo e do paradigma contratualista de sociedade, exsurge um humanismo antropocêntrico, que concebe a dignidade

${ }^{5}$ Marco Túlio Cícero é filósofo estoico e orador da Roma Antiga. 
da pessoa humana como inerente à pessoa, numa perspectiva racional e secularizada. Com as revoluções burguesas, manifestou-se o igualitarismo da dignidade. Em Rousseau, a ideia de igualdade consubstancia-se na "afirmação de que o contrato social deve instaurar um regime de plena igualdade entre os cidadãos, assegurado pela igual participação de todos na elaboração das leis e pela submissão de todas as pessoas às mesmas normas” (SARMENTO, 2016, p. 35). Coube à Kant formular o conhecido imperativo categórico, de evidente viés igualitário: “Age de tal de maneira que uses a humanidade, tanto na tua pessoa como na pessoa de qualquer outro, sempre e simultaneamente como fim, e nunca simplesmente como meio.” (KANT, 2011, p. 73). Kant fundamentou a dignidade humana na autonomia, característica universal de descobrir e se autodeterminar pela lei moral, numa perspectiva individualista.

Na contemporaneidade, em especial após a Segunda Guerra Mundial, diante dos horrores do Holocausto, retoma-se, na cultura jusfilosófica ocidental, a preocupação com os ideais humanistas. A compreensão humanista contemporânea exige, segundo Daniel Sarmento (2016, p. 40), nivelamento por cima do tratamento dados às pessoas. Houve, ainda, a adoção de uma concepção do ser humano mais real, histórico, não um indivíduo racional isolado, mas inserido em relações sociais que são constitutivas de sua identidade. Com Hegel, ressaltou-se a importância do reconhecimento intersubjetivo.

Verifica-se, no entanto, uma universalização teórica da dignidade humana e dos direitos humanos, que não foi implementada na prática.

No pós Segunda Guerra, a dignidade da pessoa humana foi consagrada como princípio jurídico, tendo sido positivado pelas normas internacionais e constituições e está consagrada em 149 constituições das 194 em vigor (SARMENTO, 2016, p. 14). No ordenamento jurídico positivo brasileiro, a Carta Magna proclamou a centralidade da dignidade da pessoa humana, valor fundamental da ordem jurídica, consoante se extrai da leitura dos princípios fundamentais e objetivos fundamentais da República Federativa do Brasil elencados, respectivamente, em seus artigos $1^{\mathrm{o}} 6$ e $3^{\mathrm{o} 7}$.

\footnotetext{
6“'Art. $1^{\circ}$ A República Federativa do Brasil, formada pela união indissolúvel dos Estados e Municípios e do Distrito Federal, constitui-se em Estado Democrático de Direito e tem como fundamentos: I - a soberania; II - a cidadania; III - a dignidade da pessoa humana; IV - os valores sociais do trabalho e da livre iniciativa; V - o pluralismo político.” (BRASIL, 1988).

7“'Art. $3^{\circ}$ Constituem objetivos fundamentais da República Federativa do Brasil: I - construir uma sociedade livre, justa e solidária; II - garantir o desenvolvimento nacional; III - erradicar a pobreza e a marginalização e reduzir as desigualdades sociais e regionais; IV - promover o bem de todos, sem preconceitos de origem, raça, sexo, cor, idade e quaisquer outras formas de discriminação.” (BRASIL, 1988).
} 
Ademais, as organizações internacionais de direitos humanos tem combatido

o hate speech, lastreando-se em instrumentos internacionais, destacando-se a Declaração Universal dos Direitos Humanos ${ }^{8}$, o Pacto Internacional para Eliminação de Todas as Formas de Discriminação Racial e a Convenção Interamericana contra Toda Forma de Discriminação e Intolerância. Esta última Convenção estabelece o firme compromisso dos Estados membros da Organização dos Estados Americanos com a erradicação total e incondicional de todas as formas de discriminação e intolerância e, malgrado ainda não ratificada pelo Brasil, oferece parâmetros para o conceito jurídico de discurso do ódio, a proteção da igualdade material, da dignidade humana e do princípio da não discriminação, cuja relevância para a legislação interna deriva da perspectiva do controle de convencionalidade e da importância do diálogo entre as jurisdições (PIOVESAN, 2012, p. 72). Nesse diapasão, é relevante compreender o Brasil como inserido no contexto internacional de proteção de direitos humanos, integrando o Sistema Interamericano, o qual, segundo Flávia Piovesan (2012, p. 83-84), consolida um constitucionalismo regional que tutela os direitos das populações da região.

A trajetória do humanismo enquanto valorização da pessoa humana constrói o conceito de dignidade da pessoa humana. O processo histórico de sua formação desenvolveuse de forma complexa e não linear, fundamentando-se ora em leis divinas, ora na natureza humana, ou ainda indicada como resultante de lutas políticas e sociais.

A dignidade da pessoa humana, princípio profundamente humanista, baseiase na valorização da pessoa e resguardo de seus direitos básicos contra toda forma de injustiça e agressão (SARMENTO, 2016, p. 15). Não se desconhece críticas ao seu grau de indeterminação. Com efeito, impende delinear o seu conteúdo para enfrentar a questão do discurso do ódio. A doutrina jurídica constitucional brasileira fornece elementos para este desiderato.

Ingo Wolfgang Sarlet refere-se às dimensões ontológica e intersubjetiva da dignidade da pessoa humana. A primeira refere-se ao valor intrínseco da pessoa. A segunda, às relações sociais intersubjetivas. A seguir, traz-se à lume seu conceito:

8A Declaração Universal dos Direitos Humanos afirma em seu preámbulo: "reconhecimento da dignidade inerentea todos os membros da família humana e dos seus direitos iguais e inalienáveis constitui o fundamento da liberdade, da justiça e da paz no mundo”. (ONU, 1948). 
[...] dignidade da pessoa humana [é] a qualidade intrínseca e distintiva reconhecida em cada ser humano que o faz merecedor do mesmo respeito e consideração por parte do Estado e da comunidade, implicando, neste sentido, um complexo de direitos e deveres fundamentais que assegurem a pessoa tanto contra todo e qualquer ato de cunho degradante e desumano, como venham a lhe garantir as condições existenciais mínimas para uma vida saudável, além de propiciar e promover sua participação ativa e corresponsável nos destinos da própria existência e da vida em comunhão com os demais seres humanos, mediante o devido respeito aos demais seres que integram a rede da vida. (SARLET, 2015, p. 73).

Maria Celina Bodin de Moraes (2010, p. 85), por sua vez, desdobra o substrato material da dignidade da pessoa humana em quatro princípios: igualdade, integridade psicofísica, liberdade e solidariedade. Sua conceituação implica, entre outros aspectos, que o sujeito moral reconhece a existência dos outros como sujeitos iguais a ele. Oscar Vilhena Vieira (2006, p. 63-69) ressaltou que da dignidade deriva a exigência moral e jurídica de reciprocidade nas relações intersubjetivas. Sustentou, também, que a dignidade impõe, além de direito, deveres que podem justificar restrições à liberdade individual em prol de um modo digno de vida.

Luís Roberto Barroso (2013, p. 67-68) circunscreve a dignidade da pessoa humana a três elementos: valor intrínseco, autonomia e valor comunitário. O valor intrínseco compreende vários direitos básicos, como o direito à vida, igualdade e integridade físicopsíquica. A autonomia abrange as dimensões pública e privada. O valor comunitário enseja restrições às liberdades individuais voltados à proteção de direitos de terceiros, da dignidade do próprio indivíduo e de valores compartilhados pela sociedade. Outrossim, Daniel Sarmentodelineia o conteúdo essencial da dignidade da pessoa humana em quatro componentes: valor intrínseco da pessoa humana, autonomia, mínimo existencial e reconhecimento (SARMENTO, 2016, p. 91-94). O reconhecimento intersubjetivo, consoante Sarmento, não denota a mera identificação do outro, envolve a "valorização da pessoa reconhecida, em atitude que lhe expressa o devido respeito. Esse direito ao igual respeito da 
identidade pessoal impõe, sob o aspecto negativo, a vedação de práticas que desrespeitam as pessoas em sua identidade, estigmatizando-as, e, sob o aspecto positivo, impõe ao Estado a adoção de medidas voltadas ao combate dessas práticas e à superação dos estigmas existentes (SARMENTO, 2016, p. 241-298).

As mencionadas doutrinas apontam em direção a um princípio essencial para a concretização da dignidade humana: a fraternidade. Da dimensão intersubjetiva da dignidade da pessoa humana de Sarlet (2015, p. 73), que situa o homem como corresponsável nos destinos da própria existência e da vida em comunhão com os demais seres humanos; do pressuposto integrante do substrato material da dignidade da pessoa humana de Maria Celina Bodin (2010, p. 85) - o reconhecimento da existência de outros como sujeitos iguais; da exigência de reciprocidade nas relações intersubjetivas apontada por Vilhena Vieira (2006, p. 63-69) decorrente da dignidade; do valor comunitário de Barroso (2016, p. 67-68) e do reconhecimento de Sarmento (2016, p. 241-298), extraem-se elementos de fraternidade.

E, conforme lição de Carlos Augusto Alcântara Machado (2014, p. 138), "Será exatamente por meio da garantia incondicional da dignidade da pessoa humana que a fraternidade será alcançada.”

\section{O discurso do ódio e o paradigma do homo sacer}

O contexto sociopolítico da atualidade reproduz, na história, o contínuo excluir do outro. Como bem ressalta Amitrano (2014, p. 86), "Mais recentemente, recriam-se na Europa figuras - ligadas intimamente a um espaço territorial e/ou determinada etnia - que traduzem novas versões do velho homo sacer do Direito Romano”. Assim, são diversos os homo sacers modernos. No entanto, em um Estado Democrático de Direito que tem por compromisso estabelecer uma sociedade fraterna, não se pode permitir essa vulneração de direitos de certos grupos e pessoas, nem mesmo com o escopo de resguardar a liberdade de expressão.

As vítimas do discurso do ódio são vulneradas concretamente, excluídas do estado de direito, sua liberdade é subtraída e sua vida perde um valor significativo. Os discursos 
de intolerância podem, em certos casos, reduzir seus destinatários ao homo sacer ${ }^{9}$ proposto Agamben (2002 apud AMITRANO, 2015, p. 80), tendo destituído o valor de sua vida. Ora, o discurso de intolerância vulnera a dignidade da vida humana, em um processo contínuo de rejeição e eliminação do outro. A exclusão promovida pela sociedade civilizada e científica de certos grupos de indivíduos, tais como os refugiados e exilados, ossocial e politicamente excluídos, é bem pontuada por Agamben como manifestação da indiferença para com a humanidade:

De fato, o que se verifica nestes cem anos que abrangem os séculos do conhecimento de da ciência, XX e XXI, são dois lados muito bem distintos, dois mundos com muros que se erguem entre pessoas e nações, territórios desiguais, indivíduos desiguais. “o homem moderno [aparece, assim,] como um animal em cuja política está em questão sua vida de ser vivente”. [...] Para a figura do homo sacer, na ambiguidade de sua existência, seu não-lugar, contemporaneamente, possui um lócus especificado. Há um espaço certo para esse ser de a-significância: o campo, o campo de refugiados, o campo de exilados, campo de deslocados; o campo de detenção. [...] O homo sacer, assim como o refugiado/apátrida, está em um conceito-limite o que permite conduzilo ao campo.Em outros termos, o Outro na sua condição de estranho/estrangeiro perpetua aquilo que o período das guerras mundiais concretizou: sua sobrevivência é vista como princípio da criminalização, “sendo primordial manifestação da indiferença para com a humanidade”, afirma Agamben. [...] O exemplo de judeus, Testemunhas de Jeová e ciganos durante a Segunda Guerra é o mais fácil para explicitar essa situação, que não se circunscreve a esses grupos. Postos fora da condição humana em função da indiferença com sua vida, todos eram homo sacers. Ademais, para

\footnotetext{
${ }^{9} \mathrm{O}$ homo sacer proposto por Agamben aparece como "um conceito que diz respeito a um ser cuja vida nada vale, uma vida matável. [...] O homo sacer é aquele cuja condição humana é minimizada a tal ponto que sua vida pode e é excluída de todos os direitos civis.” (AMITRANO, 2014, p. 80).
} 
Ana Patricia Vieira Chaves Melo \& Bricio Luis da Anunciação Melo eles foi escolhido o não-lugar: o campo. A ausência de direitos humanos representa a ausência de humanidade imputada a esses indivíduos que, na qualidade de inimigos, perderam o direito de ser pessoa. (2002 apud AMITRANO, 2014, p.85 e 90, grifo nosso)

À exclusão, contrapõem-se o reconhecimento, a fraternidade. Propõe-se, pois, a fraternidade como princípio jurídico concretizador da dignidade da pessoa humana, cuja centralidade no ordenamento jurídico e nos instrumentos internacionais não tem sido suficiente para assegurar sua eficácia social.

Importa frisar que se entende por fraternidade, na linha propugnada por Antonio Maria Baggio (2008 apud MACHADO, 2014, p. 25) não um simples sentimento, mas uma racionalidade fraterna, interpretação correta da igualdade e da diversidade humanas.

Malgrado tal princípio somente tenhaalcançado projeção políticapor ocasião da Revolução Francesa, ao compor a tríade "liberdade, igualdade e fraternidade”, sua origem remonta ao surgimento cristianismo, que inaugura uma nova ética de fraternidade, responsabilizando o ser humano perante o outro universal (MACHADO, 2014, p. 1542). Antes mesmo da Revolução Francessa, segundo pesquisas de Antonio Maria Baggio (2008 apud MACHADO, 2014, p. 24), o filósofo francês e humanista cristão Étienne de La Boétie teria feito a primeira referência conjunta aos três princípios, reconhecendo que, embora diferentes, os homens deveriam cultivar a afeição fraterna, o que os tornaria iguais. Ocorre que, enquanto os princípios da liberdade e igualdade foram desenvolvidos e concretizados, ao menos em parte, com construçãohistórica enão-linear dos direitos humanos, esqueceu-se do princípio da fraternidade ${ }^{10}$.

\footnotetext{
${ }^{10}$ Segundo Carlos Augusto Alcântara Machado, "Dos três valores, princípios ou categorias, um, a fraternidade, restou esquecida pelo antropocentrismo ou, no mínimo, oculta." Ademais, o autor ressalta serem recentes os estudos sobre a fraternidade como princípio jurídico, in verbis: "No continente europeusomente a partir do início do século XXI, conceituados professores da Universitàdegli Studi di Milano-Bicocca, da UniversitàCattolica de Milano, da Università de Catania, da ScuolaSuperiore Sant'Anna di Pisa, como AngeloMattioni, Emanuele Rossi, Andrea Bonomi, Felice Giuffrè, Anna Marzati, LidiannaDefrassi, VincezoSatta e Salvatore La Porta, investigadores na área de Direito Público [...] anunciam trabalhos jurídicos voltados ao estudo da Fraternidade como princípio jurídico.” (2014, p. 105).
} 
A Constituição Federal de 1988 reconheceu a fraternidade como categoria jurídica. Firmou o compromisso de assegurar uma sociedade fraterna, pluralista e sem preconceitos. Frise-se que o direito fraterno centra suas observações nos direitos humanos, na humanidade como um lugar comum (VIAL, 2006, p. 123). Adota-se, neste artigo,a concepção de fraternidade universal, que contempla toda a humanidade, tal como leciona Carlos Augusto Alcântara Machado (2013, p. 66-76), porquanto fundada na dignidade da pessoa humana, sem a qual não pode ser alcançada.

Zygmunt Baumant reconhece o ser humano como homeneligens, apto a tomar decisões e fazer história, pautado nos valores da justiça e solidariedade. No mundo da modernidade líquida e da visão vigilante ${ }^{11}$, admite a possibilidade de outros tipos de olhar que não nos cega para a humanidade do outro, impregnada de esperança.

Os seres humanos podem fazer a diferença, e efetivamente o fazem, podem pensar de forma não convencional e às vezes até alterar o curso da história na direção da justiça e da solidariedade. (BAUMAN, 2013, p. 130)

E, segundo o professor Eligio Resta (apud VIAL, 2006, p. 124), existe uma grande diferença entre ser homem e ter humanidade. Direitos humanos, ressalta o professor italiano, são o lugar a responsabilidade. Com efeito, é mister colocar-se no lugar do outro, enxergando-o como um outro eu. O Direito Fraterno, na medida em que propõe a ruptura do binômio amigo-inimigo nas palavras de Resta, é supedâneo para limitar a liberdade de expressão no que se refere ao discurso do ódio.

\footnotetext{
${ }^{11}$ Modernidade líquida é uma categoria consagrada na obra de Bauman. Para o sociólogo polonês, a modernidade tem se liquidificado, fluidificado de novas e diferentes maneiras e, nesse processo, duas características se destacam. Primeiramente, as formas sociais se desmancham mais depressa que a velocidade com que se criam novas formas. Em segundo lugar, poder e política estão se separando. O poder passou a existir num espaço global e extraterritorial, mas a politica continua local, incapaz de agir em nível planetário. Com efeito, o poder torna-se sem controle político. A vigilância atual também se espalha de formas até então inimagináveis, reagindo à liquidez e reproduzindo-a (BAUMAN, p. 11-13).
} 
Gize-se que o debate acerca do discurso do ódio ultrapassa o sentimento emocional e estado psicológico de suas vítimas. Trata-se da privação de direitos dos membros de minorias historicamente excluídas, o que pode gerar o silêncio e acuamento de seus titulares ou uma reação violenta, em uma cadeia circular. O discurso do ódio autoriza, portanto, restrições constitucionalmente legítimas à liberdade de expressão.

Se, por um lado, a liberdade de expressão encontra um de seus principais fundamentos na dignidade da pessoa humana, conceito central a reger toda uma ordem jurídica constitucionalizada, por outro lado, a dignidade da pessoa humana estabelece seus limites enquanto direito fundamental. Nesse diapasão, impende ressaltar que há também uma relação dialética e dinâmica entre democracia e liberdade de expressão.

Não se desconhece posições de ilustres filósofos, tais quais Ronald Dworkin (1996 p. 204), para quem a não admissão das manifestações de ódio levariam à volta da censura, de modo que qualquer controle do governo sobre a expressão de ódio seria paternalista. Para Dworkin, a liberdade de expressão deve ser estendida a todos sem distinção, cabendo aos indivíduos, como agentes morais responsáveis, formar suas opiniões. Porém, em uma sociedade em que o discurso do ódio é aceito invocando a democracia, minorias podem sentir-se constrangidas de ir à escola, caso não se trate de uma escola segregada, de falar em público ou até mesmo andar na rua, a não ser no gueto. Por conseguinte, ao invés de assegurar espaços públicos e democráticos de discussão, o discurso do ódio obsta às suas vítimas o acesso a tais espaços.

Por conseguinte, verifica-se que, na seara do discurso do ódio, os princípios democráticos da liberdade e da igualdade se opõem. A fraternidade apresenta-se como ponto de equilíbrio entre os mencionados princípios (MACHADO, 2014, p. 167), de modo a assegurar a dignidade da pessoa humana. Trata-se da etapa fraternal do conctitucionalismo, segundo o ex-minsitro Ayres Britto (2003, apud MACHADO, 2014, p. 131).

Isso porque a dignidade da pessoa humana é a fonte e fundamento de todos os direitos materialmente fundamentais, é “fundamento moral do Estado e do Direito, diretriz hermenêutica de todo o sistema jurídico, norte para ponderação de interesses, parâmetro para a validade dos atos estatais e privados, limite para o exercício de direitos [...]” (SARMENTO, 2016, p. 98-99 e 305).

Como destacou Habermas, a dignidade da pessoa humana "forma algo como o portal por meio do qual o conteúdo igualitário-universalista da moral é importado ao direito”. 
Com efeito, a moral pública deve ser albergada pelo direito, consoante preconizado por Dworkin, em sua crítica aos preceitos do positivismo preconizados por Hart (DWORKIN, 2010, p. 27-29). Isso não significa, porém, que a dignidade da pessoa humana seja um princípio absoluto. Conforme sustentado por Robert Alexy e, na doutrina pátria, por Ingo Sarlet (2011, p. 124-141) e Luís Roberto Barroso (2004, p. 3), os princípios, inclusive a dignidade da pessoa humana, são relativos, pelo que devem ser submetidos a um processo de ponderação, quando em conflito, em função das peculiaridades do caso concreto.

Com efeito, para a resolução dos conflitos que se evidenciam no discurso do ódio, faz-se necessário mais do que a promoção da tolerância, mas respeitar e honrar o outro na sua alteridade, nas suas preferências, conforme defende Zygmunt Bauman. Segundo Bauman (1999, p .16) a modernidade leva à "negação dos direitos e razões de tudo que não pode ser assimilado - a deslegitimação do outro”. No entanto,é mister aprender a viver com a diferença e, ultrapassar a tolerância para alcançar o respeito ao outro. O "ser gentil” e a tolerância que ele representa não devem ser tomados simplesmente como uma forma de tornar a "coexistência suportável e um pouco menos perigosa”, porquanto “não bastaria evitar a humilhação dos outros. É preciso, também, respeitá-los - e respeitá-los precisamente na sua alteridade, nas preferências, no seu direito de ter preferências.”(BAUMAN, 1999, p. 249).

Por outro lado, impende destacar a absoluta excepcionalidade das restrições à liberdade de expressão, reservando-seaos casos em que não seja possível a composição posterior do dano, bem como para as situações em que o valor constitucional conflitante justifique e exija a intervenção, no caso concreto, à luz do princípio da proporcionalidade. É exatamente o caso do discurso do ódio - compreendido nos limites adrede exposados, sobretudo considerada a posição central que a dignidade da pessoa humana possui no nosso ordenamento pátrio e nos instrumentos internacionais para a salvaguarda de uma sociedade pluralista e fraternal . Essa ponderação deve ser empreendida no caso concreto, tendo a dignidade da pessoa humana como norte substantivo, de modo a alcançar a sociedade fraternal ${ }^{12}$.

\footnotetext{
${ }^{12}$ Sociedade fraterna na concepção de Ricardo Hasson Sayeg (2011 apud MACHADO, 2014, 138) correspondente a uma "vindicação constitucional à antropofilia, isto é, uma sociedade que supera o antropocentrismo e descola o homem do centro do universo para o meio difuso de todas as coisas, estabelecendo, entre todos e tudo uma conexão universal [...]”.
} 
6 Conclusão

O discurso do ódio perpassa o cenário mundial da atualidade, seja na Europa, com manifestações de intolerânciae discriminação em virtude da condição de refugiado ou de imigrante ou em função de religião, seja nos Estados Unidos, onde, após campanha presidencial permeada por discursos xenófobos e racistas, recrudesceram o discurso e as práticas de intolerância.

Nesse contexto, em um momento mundial politicamente de direita, delinearam-se as imbricações entre o direito fundamental à liberdade de expressão e a democracia, de um lado, e os princípios da dignidade da pessoa humana e da fraternidade, de outro, e delimitou-se o âmbito de proteção e quais os limites do direito fundamental à liberdade de expressão, a fim de garantir mais do que tolerância - a fraternidade, como fruto do pleno desenvolvimento da dignidade da pessoa humana.

O conflito que se opera o discurso do ódio entre os princípios da liberdade de expressão e a dignidade da pessoa humana, cuja ocorrência em nosso país é por vezes velada ou negada, aponta, sob a perspectiva da constitucionalização do direito pátrio, do arcabouço da Constituição Federal de 1988 e dos tratados internacionais, para a necessidade de solucionar tais conflitos, com lastro nos princípios da dignidade da pessoa humana e da fraternidade.

O princípio da dignidade da pessoa humana alcançou posição de centralidade no ordenamento jurídico pátrio e nos instrumentos internacionais. A exemplo dos demais direitos fundamentais, aplica-se às relações entre particulares e gera para o Estado, além de direitos de abstenção, o dever de ação com o escopo de proteger a dignidade da pessoa humana contra os ataques e ameaças a ela empreendidas, tais como as que se operam no discurso do ódio, colimando a construção de uma sociedade fraternal. Com efeito, o Estado Democrático de Direito não pode simplesmente entregar ao abandono os indivíduos que possuem sua conditio humana minimizada em razão do discurso do ódio, postura incompatível com o princípio da fraternidade.

Devem-se estabelecer, portanto, restrições ao direito fundamental à liberdade de expressão dos emissores do discurso do ódio a fim de garantir a fraternidade em uma sociedade plural, à luz da dignidade da pessoa humana como critério fundante do ordenamento jurídico. 


\section{Referências}

ALEXY, Robert. Teoria de los derechos fundamentales. Tradução: Ernesto Garzón Valdés. Madrid: Centro de EstudiosConstitucionales, 1997.

AMITRANO, Georgia. O paradoxo do homo sacer: entre o abandono e o bando. Cadernos de ética e filosofia política, São Paulo, n. 23, p. 78-92, jul. 2014. Disponível em: $<$ http://www.revistas.usp.br/cefp/article/view/74747/78338>. Acesso em: 09 dez. 2016.

BAUMAN, Zygmunt. Modernidade Líquida. Tradução: Carlos Alberto Medeiros. Rio de Janeiro: Zahar, 2013.

Zahar, 1999.

Modernidade e ambivalência.Tradução: Marcus Penchel. Rio de Janeiro:

BARROSO, LUÍS ROBERTO.COLISÃOENTRE LIBERDADE DE EXPRESSÃO E DIREITOS DA PERSONALIDADE. CRITÉRIOS DE PONDERAÇÃO. INTERPRETAÇÃO CONSTITUCIONALMENTE ADEQUADA DO CÓDIGO CIVIL E DA LEI DE IMPRENSA. REVISTA DE DIREITO ADMINISTRATIVO, RIO DE JANEIRO;N.235, P. 1-36, JAN./MAR 2004. DISPONÍVEL

EM: <HTTP://BIBLIOTECADIGITAL.FGV.BR/OJS/INDEX.PHP/RDA/ARTICLE/VIEW/45123 /45026>. ACESSO EM: 19 NOV. 2016.

A dignidade da pessoa humana no direito constitucional contemporâneo: a construção de um conceito jurídico à luz da jurisprudência mundial. Belo Horizonte: Fórum, 2013.

BORGES, LILIANA. ESCOLAS REFORÇAM SERVIÇOS DE APOIO A MINORIAS DEPOIS DA VITÓRIA DE TRUMP. PUBLICO ONLINE, LISBOA, 14 NOV. 2016. DISPONÍVEL EM: <HTTPS://WWW.PUBLICO.PT/MUNDO/NOTICIA/ESCOLASREFORCAM-SERVICOS-DE-APOIO-A-MINORIAS-DEPOIS-DA-VITORIA-DETRUMP-1751125>. ACESSO EM:17 NOV. 2016.

BRASIL. Supremo Tribunal Federal. HC 82.424/RS. Relator: Ministro Moreira Alves, Brasília, 17 de setembro de 2004. Disponível em: < http://www.stf.jus.br/portal/jurisprudencia/listarJurisprudencia.asp?s1=\%28HC\%24.SCLA.+E +82424.NUME.\%29+OU+\%28HC.ACMS.+ADJ2+82424.ACMS.\%29\&base=baseAcordaos \&url=http://tinyurl.com/az3e35m>. Acesso em:14 nov. 2016.

BRUGGER, Winfried. Proibição ou proteção do discurso do ódio? Algumas observações sobre o direito alemão e o americano. Direito Público, Porto Alegre, n. 15, p. 117-136, jan./mar. 2011. 

CAÑAS, GABRIELA. EM TRÊS DIAS, 'SELVA' DOS MIGRANTES EM CALAIS, NA FRANÇA, FICA QUASE VAZIA. EL PAÍS ONLINE, CALAIS, 26 OUT. 2016. DISPONÍVEL <HTTP://BRASIL.ELPAIS.COM/BRASIL/2016/10/26/INTERNACIONAL/1477480700_51 7094.HTML>. ACESSO EM: 17 NOV. 2016.

DWORKIN, Ronald. O direito da liberdade: a leitura moral da Constituição norte-americana. São Paulo: Martins Fontes, 2006.

. Levando os direitos a sério. Tradução: Nelson Boeira. 3. ed. São Paulo: WMF Martins Fontes, 2010.

EUA. Declaração de Independência dos Estados Unidos da América, 1776. Disponível em <https://www.wdl.org/pt/item/109/>. Acesso em: 20 nov. 2016.

KANT, Emanuel. 2011. Fundamentação da metafísica dos costumes. Tradução Pedro Quintela. Lisboa: Edições 70, 2011.

MACHADO, Carlos Augusto Alcântara. A fraternidade e o direito constitucional brasileiro anotações sobre a incidência e aplicabilidade do princípio/valor fraternidade no direito constitucional brasileiro a partir da sua referência no preâmbulo da Constituição federal de 1988. In: PIERRE, Luiz A. A. et al (Org.). A fraternidade como categoria jurídica, São Paulo: Cidade Nova, 2013.

. A Garantia Constitucional da Fraternidade: Constitucionalismo Fraternal. Tese (Doutorado em Direito) - Pontifícia Universidade Católica de São Paulo. São Paulo, 2014. Disponível em: $<$ https://sapientia.pucsp.br/bitstream/handle/6436/1/Carlos\%20Augusto\%20Alcantara\%20Ma chado.pdf $>$. Acesso em: 20 nov. 2017.

MAIA, MARIA CAROLINA. MISS BRASIL 2017: 'RACISMO É CRIME E EU ESTOU AQUI PARA LUTAR'.REVISTA VEJA, SÃO PAULO, 22 AGO. 2017. DISPONÍVEL EM: $<$ HTTPS://VEJA.ABRIL.COM.BR/BLOG/VEJA-GENTE/MISS-BRASIL-2017-RACISMOE-CRIME-E-EU-ESTOU-AQUI-PARA-LUTAR/> . ACESSO EM: 20 NOV. 2017.

MORAES, Maria Celina Bodin de. O princípio da dignidade da pessoa humana. Na medida da pessoa humana: estudos de direito civil-constitucional. Rio de Janeiro: Renovar, 2010.

MEYER-PFLUG, Samantha Ribeiro. Liberdade de expressão e discurso do ódio: racismo, discriminação, preconceito, pornografia, financiamento das atividades artísticas e das campanhas eleitorais. São Paulo: Revista dos Tribunais, 2009.

OEA. Convenção Interamericana contra Toda Forma de Discriminação e Intolerância. Guatemala, 2013. Disponível em: <http://dai-mre.serpro.gov.br/atosinternacionais/multilaterais/convencao-interamericana-contra-toda-forma-de-discriminacao-eintolerancia/ > . Acesso em: 22 nov. 2016. 
ONU. Declaração Universal dos Direitos do Homem. Paris, 1948. Disponível em: <http://www.onu-brasil.org.br/documentos_direitoshumanos.php>. Acesso em: 19 nov. 2016.

POPPER, Karl Raimund. A sociedade aberta e seus inimigos. Tradução: Milton Machado. 1. ed. Belo Horizonte: Itatiaia, 1987. 2 t.

PIOVESAN, Flávia. Direitos humanos e justiça internacional: um estudo comparativos dos sistemas regionais, europeu, interamericano e africano. 3. ed. São Paulo: Saraiva, 2012.

ROBL FILHO; SARLET, Ingo Wolfgang. Estado democrático de direito e os limites da liberdade de expressão na constituição federal de 1998, com destaque para o problema na sua colisão com outros direitos fundamentais, em especial, com os direitos de personalidade. Constituição, economia e desenvolvimento: Revista da academia brasileira de direito constitucional, Curitiba, v. 8, n. 14, p. 112-142, jan./jun. 2016.

SAHUQUILLO, MARÍA. COMEÇAM AS NOVAS EXPULSÕES DE REFUGIADOS DA UNIÃO EUROPEIA. EL PAÍS ONLINE, BRUXELAS, 3 ABR. 2016. DISPONÍVEL EM: $<$ HTTP://BRASIL.ELPAIS.COM/BRASIL/2016/04/03/INTERNACIONAL/1459712252_60 5155.HTML>. ACESSO EM: 17 NOV. 2016.

SAMPAIO, José Adércio Leite. Teoria da Constituição e dos direitos fundamentais. Belo Horizonte: Del Rey, 2013.

SÁNCHEZ-VALLEJO, MARÍAANTONIA. ESCOLARIZAÇÃO DE CRIANÇAS REFUGIADAS NA GRÉCIA PROVOCA REJEIÇÃO SOCIAL. EL PAÍS ONLINE, ATENAS, 17 OUT. 2016. DISPONÍVEL <HTTP://BRASIL.ELPAIS.COM/BRASIL/2016/10/15/INTERNACIONAL/1476520624_71 3589.HTML>. ACESSO EM:17 NOV. 2016.

SANTANA, Cássia.WhatsApp cria xenofobia contra sergipanos.Diário de Pernambuco, Recife, 02 mai. 2016.2 Disponível em: $<$ http://www.infonet.com.br/noticias/cidade//ler.asp?id=185954 >. Acesso em: 20 nov. 2017.

SARLET, Ingo Wolfgang. A Eficácia dos direitos fundamentais: uma teoria geral dos direitos fundamentais na perspectiva constitucional. 12. ed. Porto Alegre: Livraria do Advogado, 2015.

Dignidade da pessoa humana e direitos fundamentais na constituição federal de 1988. 9. ed. rev. e atual. Porto Alegre: Livraria do Advogado, 2011.

SARLET, Ingo Wolfgang; MARINONI, Luiz Guilherme; MITIDIERO, Daniel, 2015. Curso de direito constitucional. 4. ed. São Paulo: Saraiva, 2015.

SARMENTO, Daniel. A liberdade de expressão e o problema do "hate speech". Revista de direito do Estado, Rio de Janeiro, ano 1, n. 4, out./dez. 2006. 
Dignidade da pessoa humana: conteúdo, trajetórias e metodologia. 2. ed. Belo

Horizonte: Fórum, 2016.

SCHÄFER, Gilbert; LEIVAS Paulo Gilberto Cogo; DOS SANTOS, Rodrigo Hamilton. Discurso de ódio: da abordagem conceitual ao discurso parlamentar. Revista de informação legislativa, Brasília, ano 52, p. 143-158, jul./set. 2015.

SILVA, Rosane Leal da; NICHEL, Andressa; MARTINS, Anna Clara Lehmann; BORCHARDT CarliseKolbe Borchardt. Discurso do ódio em redes sociais: jurisprudência brasileira. Revista de direito GV, São Paulo, v.7, n. 2, jul./dez. 2011.

SILVA, Virgílio Afonso da. A constitucionalização do direito. Os direitos fundamentais nas relações entre particulares. 1. ed., $4^{a}$ tiragem. São Paulo: Malheiros, 2014.

Direitos fundamentais: conteúdo essencial, restrições e eficácia. 2. ed. São Paulo: Malheiros, 2010.

- O conteúdo essencial dos direitos fundamentais e a eficácia das normas constitucionais. Revista de direito do estado, Brasília, n. 54, p. 23-51, out./dez. 2006.

SÓFOCLES.

Antígona.

Disponível

em:

<http://www.ebooksbrasil.org/adobeebook/antigone.pdf>. Acesso em 10 set. 2017.

U.S. SUPREME COURT.Brandenburg vs. Ohio, 395, U. S. 444, 1969.Disponívelem: <http://supreme.justia.com/cases/federal/us/395/444/case.html>. Acessoem: 18 nov. 2016.

.Chaplinsky vs. State of New Hampshire, 315 U. S. 568, 1942.Disponívelem: <https://www.law.cornell.edu/supremecourt/text/315/568>Acessoem: 11 dez. 2016.

.Doe vs. Michigan 721315 U. S. 852, 1989.Disponívelem: <http://www.bc.edu/bc_org/avp/cas/comm/free_speech/doe.html>Acessoem: 11 dez. 2016.

.R.A.V. vs. City of Saint Paul, 505 U. S. 377, 1992.Disponívelem: <http: //www. law. cornell. edu/ supct/html/90-7675.ZS.html>Acessoem: 11 dez. 2016.

.Texas v. Johnson 491 U. S. 39, 1989.Disponívelem: <https://www.law.cornell.edu/supremecourt/text/491/397> Acessoem: 11 dez. 2016.

VIAL, Sandra Regina Martini. Direito fraterno na sociedade cosmopolita. Revista do Instituto de Pesquisas e Estudos, Bauru, v. 1, n. 46, p. 119-134, jul./dez. 2006.

VIEIRA, Oscar Vilhena. Direitos fundamentais: uma leitura da jurisprudência do STF. São Paulo: Malheiros, 2006.

WOLKMER, Antonio Carlos (Coord). Fundamentos do humanismo jurídico no ocidente. Barueri: Manole Editora, 2005. 